\title{
Effect of Rake Angle on Stress, Strain and Temperature on the Edge of Carbide Cutting Tool in Orthogonal Cutting Using FEM Simulation
}

\author{
Hendri Yanda ${ }^{1}$, Jaharah A. Ghani ${ }^{2}$ \& Che Hassan Che Haron ${ }^{3}$ \\ ${ }^{1}$ Department of Mechanical Engineering, Faculty of Engineering, Andalas University \\ ${ }^{2,3}$ Department of Mechanical and Materials Engineering, Faculty of Engineering and \\ Built Environment, Universiti Kebangsaan Malaysia \\ Email: hendri.yanda@ft.unand.ac.id
}

\begin{abstract}
Demand for higher productivity and good quality for machining parts has encourage many researchers to study the effects of machining parameters using FEM simulation using either two or three dimensions version. These are due to advantages such as software package and computational times are required. Experimental work is very costly, time consuming and labor intensive. The present work aims to simulate a three-dimensional orthogonal cutting operations using FEM software (deform-3D) to study the effects of rake angle on the cutting force, effective stress, strain and temperature on the edge of carbide cutting tool. There were seven runs of simulations. All simulations were performed for various rake angles of $-15 \mathrm{deg},-10 \mathrm{deg},-5 \mathrm{deg}, 0 \mathrm{deg},+5 \mathrm{deg},+10$ $\mathrm{deg}$, and $+15 \mathrm{deg}$. The cutting speed, feed rate and depth of cut (DOC) were kept constant at $100 \mathrm{~m} / \mathrm{min}, 0.35 \mathrm{~mm} / \mathrm{rev}$ and $0.3 \mathrm{~mm}$ respectively. The work piece used was ductile cast iron FCD500 grade and the cutting tool was DNMA432 series (tungsten, uncoated carbide tool, $\mathrm{SCEA}=0$; and radius angle $55 \mathrm{deg}$ ). The analysis of results show that, the increase in the rake angle from negative to positive angle, causing the decrease in cutting force, effective stress and total Von Misses strain. The minimum of the cutting force, effective stress and total Von Misses strain were obtained at rake angle of $+15 \mathrm{deg}$. Increasing the rake caused higher temperature generated on the edge of carbide cutting tool and resulted in bigger contact area between the clearance face and the workpiece, consequently caused more friction and wear. The biggest deformation was occurred in the primary deformation zone, followed by the secondary deformation zone. The highest stress was also occurred in the primary deformation zone. But the highest temperature on the chip usually occurs in secondary deformation zone, especially in the sliding region, because the heat that was generated in the sticking region increased as the workpiece was adhered by the tool and later it was sheared in high frictional force.
\end{abstract}

Keywords: cutting force; deform-3D; effective stress; finite element method; orthogonal cutting; rake angle; total Von Misses strain. 


\section{Introduction}

Finite Element Analysis (FEA) technique was first introduced in 1960s and has been widely used in designing tools and forming processes. Based on the success of FEM simulations for bulk forming processes, many researchers developed their own FEM codes to analyze metal cutting processes during the early 1980s up to now (Marusich, et al. [1]; Cerenitti, et al. [2][3]; Xie, et al. [4]; Shet [5]; and Jawahir [6]). Cerenitti, et al. [2] assumed a rigid sharp tool and elasto-plastic workpiece, and defined a node separation criterion based on the geometry of the element approaching the edge of cutting tool. Cerenitti, et al. [2] used an early version of a commercial implicit FEM code DEFORM$2 \mathrm{D}^{\mathrm{TM}}$. This code uses four-node quadrilateral elements and is based on static Lagrangian formulation. Columbus [7] introduced DEFORM-3D ${ }^{\mathrm{TM}}$ code that has been commonly used by researchers and industry in machining simulation. Applications of FEM models for machining can be divided into six groups: a) tool edge design, b) tool wear, c) tool coating, d) chip flow, e) burr formation and f) residual stress and surface integrity. The direct experimental approach to study machining processes is expensive and time consuming. For solving this problem, the finite element methods are most frequently used. Mackerle [8] proved that modeling tool wear using FEM has advantages over conventional statistical approach because it requires less experimental effort and it provides useful information such as deformations, stress, strain and temperature in chip and the workpiece, as well as the cutting force, tool stress and temperature on the tool working under specific cutting parameter.

This paper presents the application of FEM simulation to predict the effect of rake angle on cutting force, effective stress, total Von Misses strain and temperatures on the edge of carbide cutting tool in the orthogonal machining process.

\section{Methodology}

Seven runs of simulation were conducted for various design of rake angles in positive rake angles $(+15,+10$, and $+5 \mathrm{deg}), 0 \mathrm{deg}$, and negative rake angles $(-5$, -10 , and, $-15 \mathrm{deg}$ ). The machining parameter, like the cutting speed, feed rate and depth of cut, were kept constant at $100 \mathrm{~m} / \mathrm{min}, 0.35 \mathrm{~mm} / \mathrm{rev}$ and $0.3 \mathrm{~mm}$ respectively as given in Table 1 .

The work piece was ductile cast iron FCD500 grade and the cutting tool used was DNMA432 series (tungsten, uncoated carbide tool, $\mathrm{SCEA}=0$; and radius angle of $55 \mathrm{deg}$ ). This material was chosen as the workpiece material in this study because it was widely used in automotive component. Table 2 shows the composition of ductile cast iron FCD500 grade. 
Effect of Rake Angle on the Edge of Carbide Cutting Tool 181

Table 1 Input parameters in the simulation process.

\begin{tabular}{ll}
\hline Parameters & \\
\hline Cutting speed & $100 \mathrm{~m} / \mathrm{min}$ \\
Feed rate & Kept constant at $0.35 \mathrm{~mm} / \mathrm{rev}$ \\
Depth of cut (DOC) & Kept constant at $0.3 \mathrm{~mm}$ \\
\hline
\end{tabular}

Table 2 Composition of ductile cast iron FCD500 grade.

\begin{tabular}{llllllllllll}
\hline \multicolumn{10}{c}{ Element percentage (\%) } \\
\hline $\mathrm{C}$ & $\mathrm{Si}$ & $\mathrm{S}$ & $\mathrm{P}$ & $\mathrm{Mn}$ & $\mathrm{Ni}$ & $\mathrm{Cr}$ & $\mathrm{Mg}$ & $\mathrm{Cu}$ & $\mathrm{Mg}$ & $\mathrm{Al}$ & $\mathrm{Co}$ \\
\hline 2.77 & 1.26 & 0.11 & 0.036 & 1.24 & 0.26 & 0.27 & 0.09 & 0.18 & 0.127 & 0.063 & 0.073 \\
\hline Source. Sirim 2008 & \multicolumn{10}{c}{ Sim }
\end{tabular}

Source: Sirim, 2008

Figure 1 shows the geometry and schematic of orthogonal cutting condition model for the rake angle of $+15 \mathrm{deg}$. The flow stress model used was the equation given by Oxley [9] as shown in Table 3 .

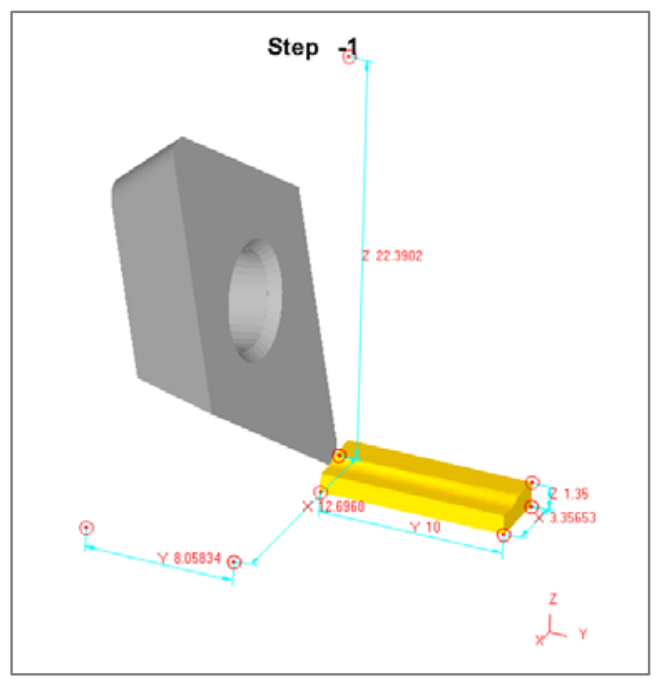

Figure 1 Geometry and schematic of the orthogonal cutting condition model for rake angle of $+15 \mathrm{deg}$.

In these simulations, the tools were defined to be an elastic body and isothermal, so the mechanical and thermal properties and also boundary condition for simulation model are given in Table 4.

Table 3 Flow stress models used in simulation.

\begin{tabular}{llll}
\hline Material Model & Equation for flow stress $\sigma$ models & Material constants & Variables \\
\hline Oxley model & $\sigma=\sigma_{1} \varepsilon^{n}$ & $\sigma_{1}, \mathrm{n}=f\left(T_{\text {mod }}\right)$ & $\varepsilon, \dot{\varepsilon}, T$ \\
\hline
\end{tabular}


Table 4 Mechanical and thermal properties and boundary condition for the simulation model.

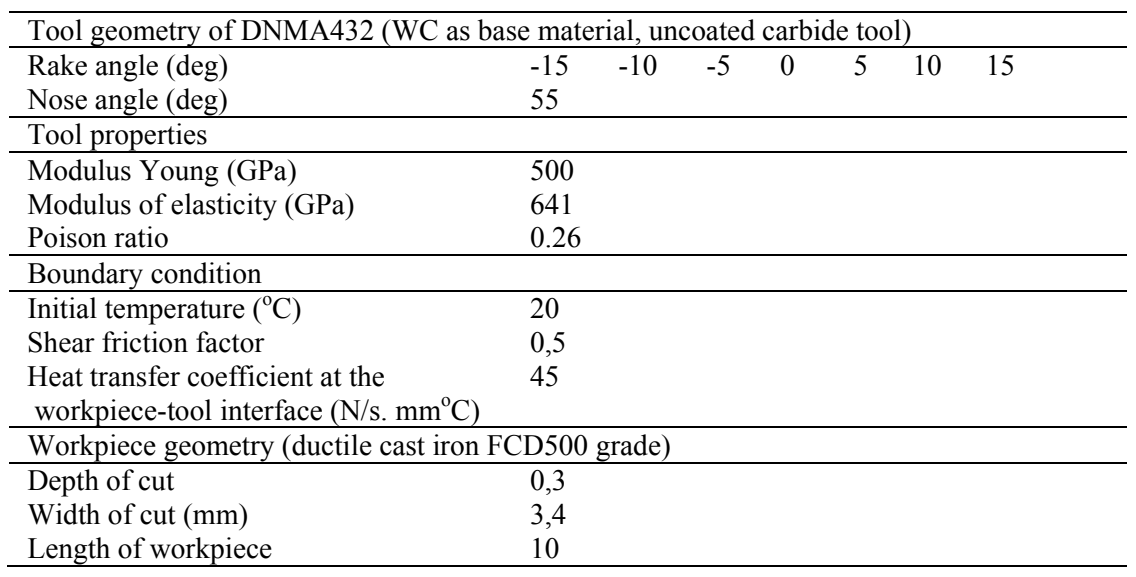

The chosen cutting tool insert carbide was DNMA432 series that has a nose angle of $55 \mathrm{deg}$ and without use of coolant. Using deform 3D, seven model of cutting tools were set up in positive rake angle $(+15,+10$, and $+5 \mathrm{deg}), 0 \mathrm{deg}$, and in negative rake angle $(-5,-10$, and $-15 \mathrm{deg})$ as shown in Figure 2.

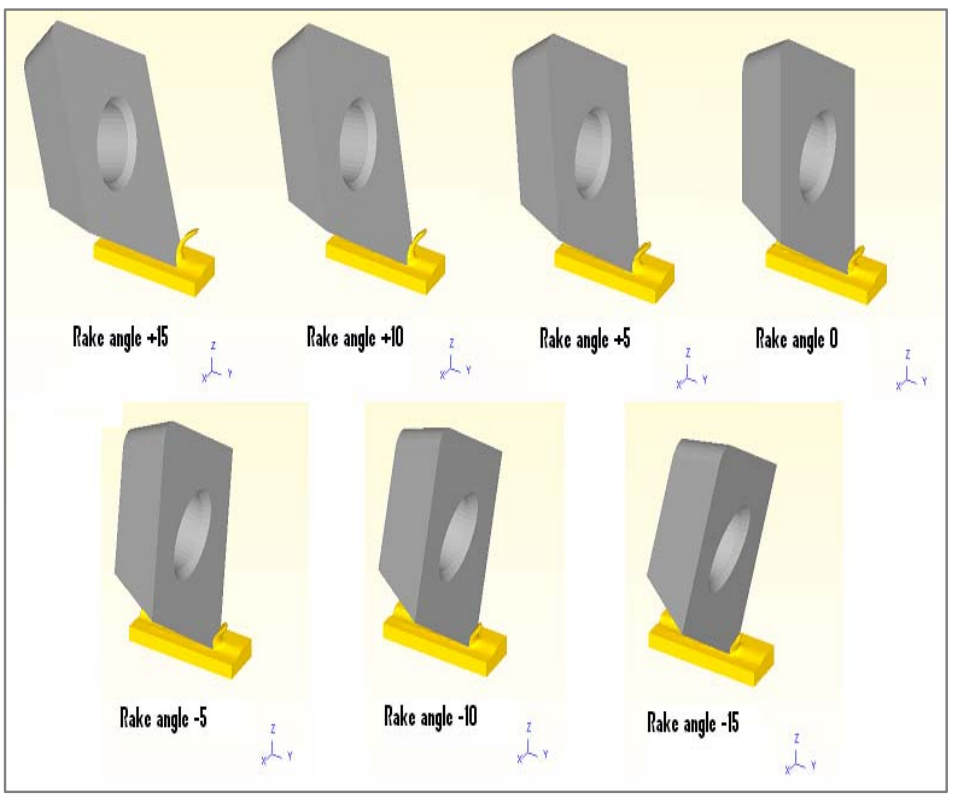

Figure 2 Various set up of rake angles in positive section $(+15,+10$, and $+5 \mathrm{deg}$, $0 \mathrm{deg}$, and negative section $(-5,-10$, and $-15 \mathrm{deg})$. 
Effect of Rake Angle on the Edge of Carbide Cutting Tool 183

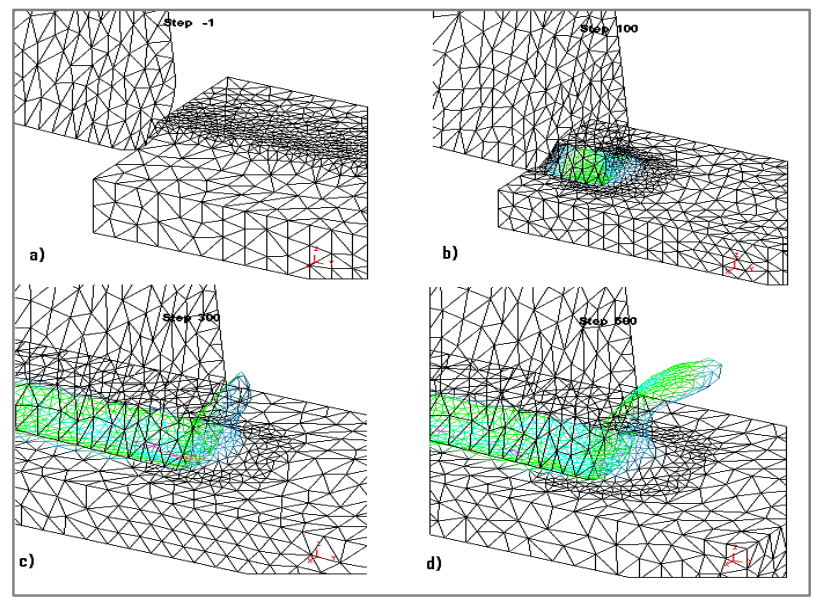

Figure 3 (a) Initial mesh and tool indentation, (b) Chip formation at step 100,(c) Chip formation at step 300, (d) Developed continues chip at step 500.

The chip formation from initial mesh and tool indentation in the beginning of cutting process until the developed continues chip formations at step 100, 300 and 500 are as illustrated in Figure 3a, 3b, 3c and 3d respectively.

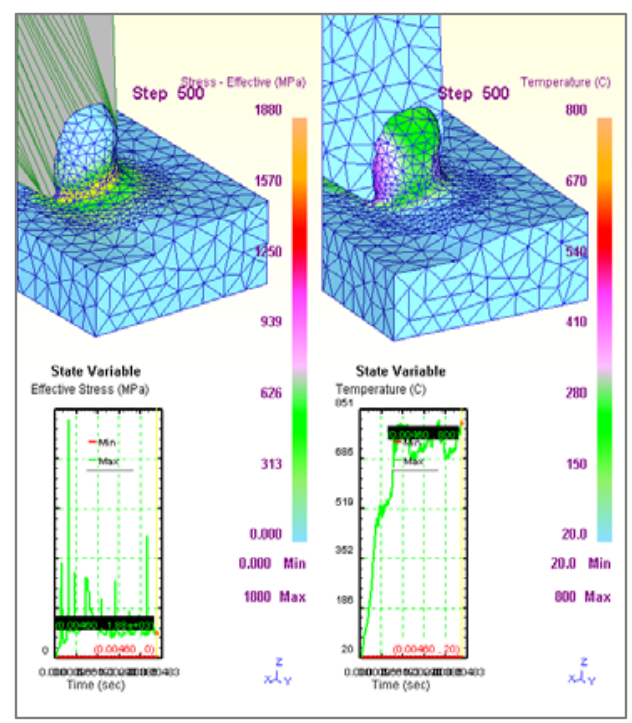

Figure 4 Example of the transient simulation result for the cutting speed of 100 $\mathrm{m} / \mathrm{min}$ and rake angle of $+5 \mathrm{deg}$ (after running in 500 steps). 
The workpiece and the tool are characterized by non uniform mesh distribution in the simulation. Very small element is required in the contact area between tool and workpiece because of very large temperature gradient and stress that will be developed in this region during the simulation. Figure 4 shows an example of transient simulation result for rake angle of +15 , the cutting speed of $100 \mathrm{~m} / \mathrm{min}$, feed rate of $0.35 \mathrm{~mm} / \mathrm{rev}$ and DOC of $0.3 \mathrm{~mm}$, at 500 steps of simulation running. The simulations were done in two series. First, simulations were carried out to investigate and analyze the tool stress, strain and temperature on the edge of carbide cutting tool. Second series, simulations were performed to investigate the workpiece and chip deformation. The results of these simulations were the stress, strain and generated temperature on chip formation and workpiece. Both series of simulation results, cutting force, the effective stress, strain and generated temperature were studied and analyzed.

\section{$3 \quad$ Results and Discussion}

\subsection{Effects on Stress, Strain and Generated Temperature on The Edge of Carbide Cutting Tool}

Figures 5 and 6 show the effective stress and the total Von Misses strain on the edge of carbide cutting tool for a rake angle of +15 deg; cutting speed of 100 $\mathrm{m} / \mathrm{min}$, feed rate of $0.35 \mathrm{~mm} / \mathrm{rev}$ and depth of cut of $0.3 \mathrm{~mm}$. The highest effective stress of $266 \mathrm{MPa}$ was reached at contour line I, followed by $233 \mathrm{MPa}$ at contour line $\mathrm{H}$, and reduced to minimum value of $33.3 \mathrm{MPa}$ at contour line $\mathrm{B}$, then followed by other areas around the carbide tool that experienced the effective stress of $0 \mathrm{MPa}$ (Figure 5).

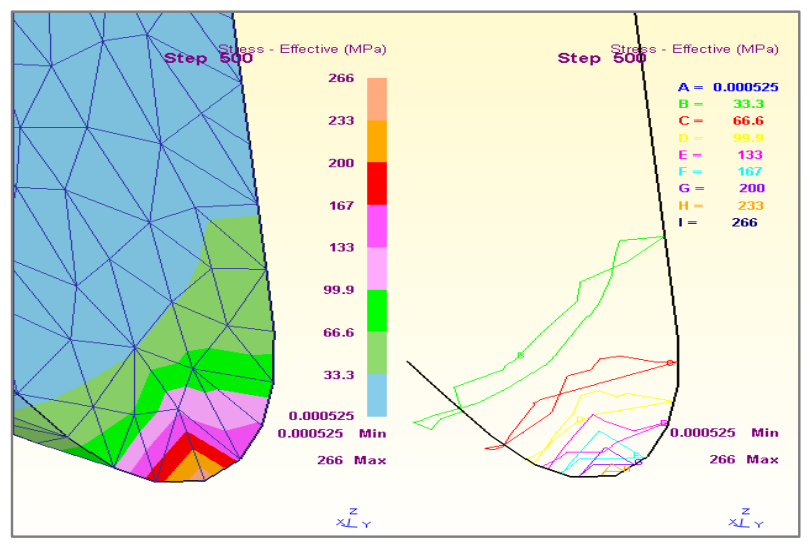

Figure 5 Effective stress at the edge of carbide cutting tool for rake angle of + $15 \mathrm{deg}$, cutting speed of $100 \mathrm{~m} / \mathrm{min}$, feed rate of $0.35 \mathrm{~mm} / \mathrm{rev}$ and DOC of 0.3 $\mathrm{mm}$. 
Similarly, the highest of total strain von misses of $0.000386 \mathrm{~mm} / \mathrm{mm}$ was reached at contour line I and followed by $0.000338 \mathrm{~mm} / \mathrm{mm}$ at contour line $\mathrm{H}$ etc., the minimum of total Von Misses strain was $0.0000483 \mathrm{~mm} / \mathrm{mm}$ at contour line $\mathrm{B}$, followed by other areas around the carbide tool that had zero value of strain (Figure 6).

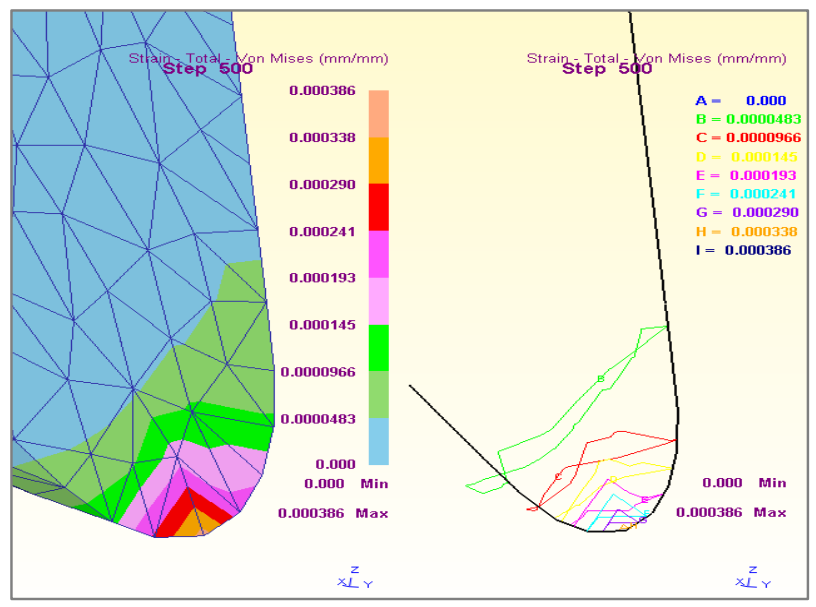

Figure 6 Total Von Misses strain at the edge of carbide cutting tool for rake angle of $+15 \mathrm{deg}$, cutting speed of $100 \mathrm{~m} / \mathrm{min}$, feed rate of $0.35 \mathrm{~mm} / \mathrm{rev}$ and DOC of $0.3 \mathrm{~mm}$.

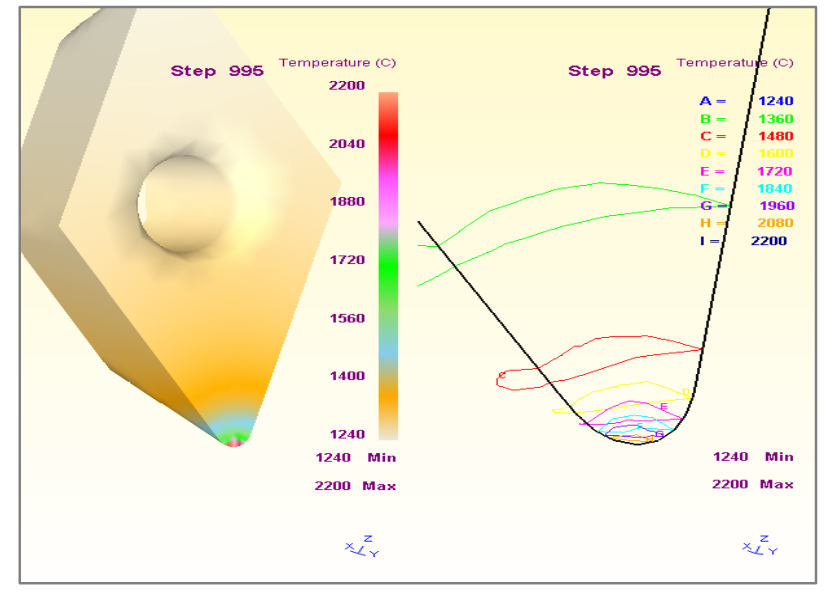

Figure 7 Generated temperature on the edge of carbide cutting tool for rake angle of $+15 \mathrm{deg}$, cutting speed of $100 \mathrm{~m} / \mathrm{min}$, feed rate of $0.35 \mathrm{~mm} / \mathrm{rev}$ and DOC of $0.3 \mathrm{~mm}$. 
The reasonable temperature occurred on the edge of carbide cutting tool were found by running at steady state simulation until 1000 steps. The temperature distribution is shown in Figure 7 where the highest of temperature occurred at the end of the cutting edge around $2200^{\circ} \mathrm{C}$ (contour line I), followed by contour line $\mathrm{H}$ around $2080^{\circ} \mathrm{C}$ etc., and the minimum temperature was $1360^{\circ} \mathrm{C}$ (contour line B), followed by other area of the carbide tool at temperature of $1240^{\circ} \mathrm{C}$.

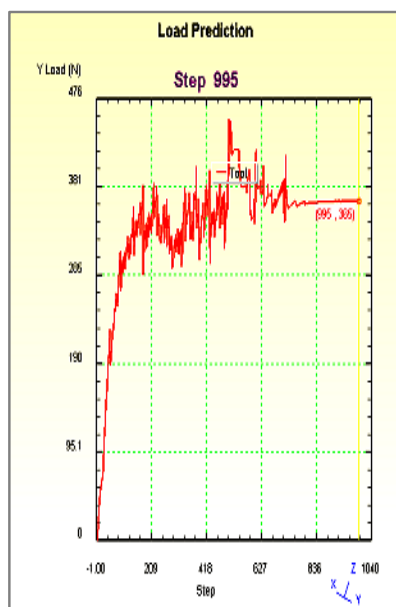

a). $y$ - cutting force

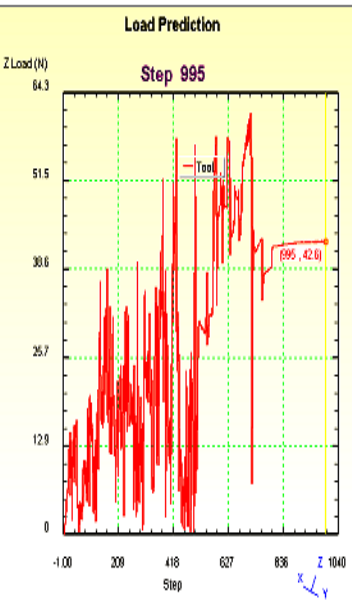

b). $z$ - cutting force

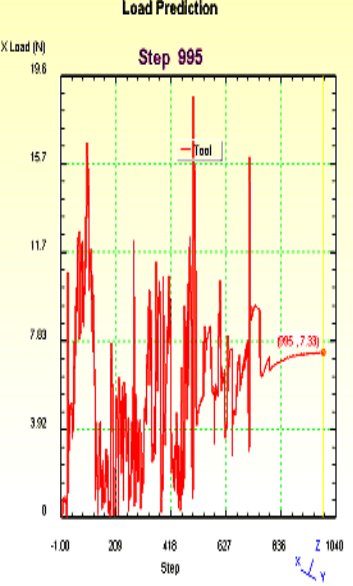

c). $\mathrm{X} \cdot$ cutting force

Figure 8 The generated main cutting force in three directions during the cutting simulation processes (rake angle of $+15 \mathrm{deg}$, cutting speed of $100 \mathrm{~m} / \mathrm{min}$, feed rate of $0.35 \mathrm{~mm} / \mathrm{rev}$ and DOC of $0.3 \mathrm{~mm}$. a) $\mathrm{y}$-cutting force, b) z-cutting force, and c) $\mathrm{x}$-cutting force.

Figure $8 \mathrm{a}, 8 \mathrm{~b}$ and $8 \mathrm{c}$ show the main cutting force generated in $\mathrm{y}, \mathrm{z}$ and $\mathrm{x}$ directions respectively during the cutting simulation processes for the rake angle of $+15 \mathrm{deg}$; cutting speed of $100 \mathrm{~m} / \mathrm{min}$, feed rate of $0.35 \mathrm{~mm} / \mathrm{rev}$ and depth of cut $0.3 \mathrm{~mm}$. The cutting forces were fluctuating in the transient simulation, and remained constant in steady state simulation (above 500 steps), the measured value in y direction was around $365 \mathrm{~N}$ and followed by $\mathrm{z}$ and $\mathrm{x}$-directions of $42.6 \mathrm{~N}$ and $7.33 \mathrm{~N}$ respectively (Figure 7).

The other simulation results of the cutting force (in y-direction), effective stress, total Von Misses strain and generated temperature for other variations of rake angles are shown in Table 5. 
Effect of Rake Angle on the Edge of Carbide Cutting Tool 187

Table 5 The cutting force in y axis, effective stress, and total Von Misses strain and generated temperature on the edge of carbide cutting tool in various rake angles.

\begin{tabular}{ccccccccc}
\hline No & $\begin{array}{c}\text { Rake } \\
\text { angle } \\
{[\mathrm{deg}]}\end{array}$ & $\begin{array}{c}\text { Cutting } \\
\text { speed } \\
{[\mathrm{m} / \mathrm{min}]}\end{array}$ & $\begin{array}{c}\text { Feed rate } \\
{[\mathrm{mm} / \mathrm{rev}]}\end{array}$ & $\begin{array}{c}\text { DOC } \\
{[\mathrm{mm}]}\end{array}$ & $\begin{array}{c}\text { Cut. } \\
\text { force } \\
{[\mathrm{N}]}\end{array}$ & $\begin{array}{c}\text { Eff. } \\
\text { Stress } \\
{[\mathrm{MPa}]}\end{array}$ & $\begin{array}{c}\text { Total. Von } \\
\text { Misses strain } \\
{[\mathrm{mm} / \mathrm{mm}]}\end{array}$ & $\begin{array}{c}\text { Temp } \\
{\left[{ }^{\circ} \mathrm{C}\right]}\end{array}$ \\
\hline 1 & +15 & 100 & 0.35 & 0.3 & 365 & 266 & 0.000386 & 2200 \\
2 & +10 & 100 & 0.35 & 0.3 & 451 & 304 & 0.00041 & 1770 \\
3 & +5 & 100 & 0.35 & 0.3 & 357 & 357 & 0.000484 & 1560 \\
4 & 0 & 100 & 0.35 & 0.3 & 554 & 554 & 0.000754 & 1170 \\
5 & -5 & 100 & 0.35 & 0.3 & 539 & 539 & 0.000735 & 1120 \\
6 & -10 & 100 & 0.35 & 0.3 & 666 & 666 & 0.000909 & 1010 \\
7 & -15 & 100 & 0.35 & 0.3 & 774 & 774 & 0.00105 & 981 \\
\hline
\end{tabular}

The prediction of the cutting force, effective stress, total Von Misses strain and generated temperature on the edge of carbide cutting tool for various rake angles are shown in Figures 9, 10, 11 and 12 respectively.

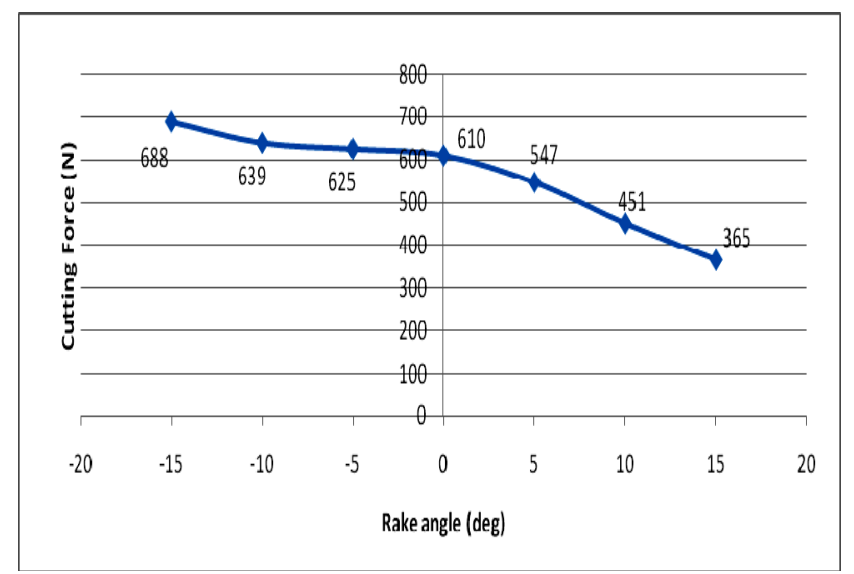

Figure 9 The cutting force at the edge of carbide cutting tool in various rake angles of $+15,+10,+5 \mathrm{deg}$ (positive section), $0 \mathrm{deg}$, and rake angle of $-5,-10$, and $-15 \operatorname{deg}$ (negative section).

As shown in Figure 9, the cutting force decreases while rake angles increases. Transition from the rake angle of -15 deg to +15 deg caused the decrease of the cutting force from $688 \mathrm{~N}$ to $365 \mathrm{~N}$. In other words, the increase of the rake angle from 0 deg to +15 deg had reduced the cutting force from $610 \mathrm{~N}$ to $365 \mathrm{~N}$, on the other hand, increasing the rake angle had increased the cutting from 610 $\mathrm{N}$ to $688 \mathrm{~N}$. 


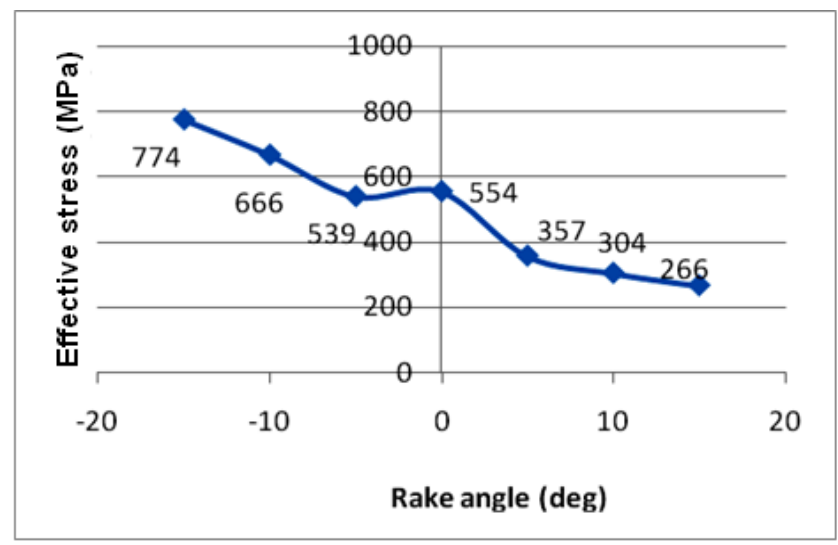

Figure 10 The effective stress on cutting edge in positive rake angle $(+15,+10$, and $+5 \mathrm{deg}), 0 \mathrm{deg}$, and negative rake angle (- 5, -10, and $-15 \mathrm{deg})$.

This phenomenon is agreeable with the experiment done by Gunay, et al. [10]. According to him, the main cutting force was reduced by increasing the rake angle in positive direction and was increased by increasing rake angle in negative direction.

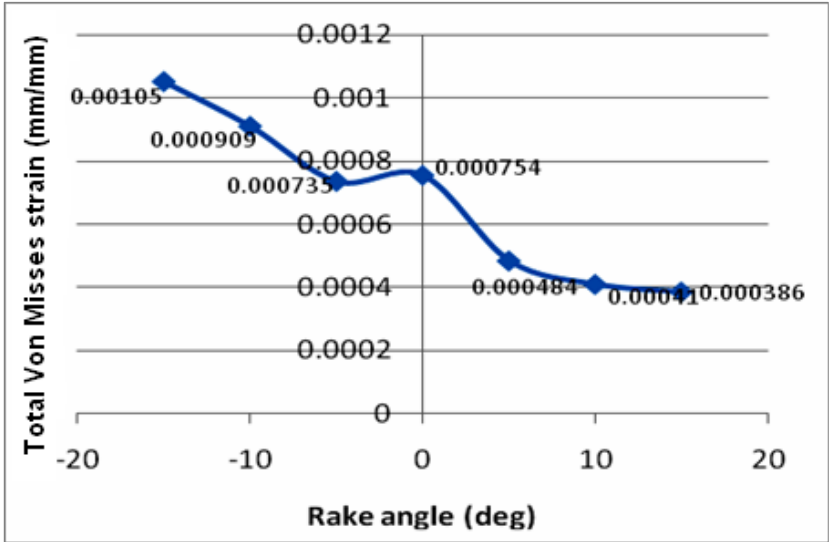

Figure 11 The total Von Misses strain on cutting edge in positive rake angle $(+15,+10$, and $+5 \mathrm{deg}), 0 \mathrm{deg}$, and negative rake angle $(-5,-10$, and $-15 \mathrm{deg})$.

Figures 10 and 11 show the affective stress and the total Von Misses strain on the edge of carbide cutting tool in negative rake angle $(+15,+10$, and $+5 \mathrm{deg})$, $0 \mathrm{deg}$, and positive rake angle $(-5,-10$, and $-15 \mathrm{deg})$. The trend was similar for 
effective stress and total Von Misses strain plots, i.e. increase the rake angle in positive direction had decreased the effective stress from 554 to $226 \mathrm{MPa}$ and total Von Misses strain from 0.000754 to $0.000386 \mathrm{~mm} / \mathrm{mm}$ respectively. Whereas, increasing the rake angle in negative section, had increased the effective stress to the maximum, i.e. $554 \mathrm{MPa}$ to $774 \mathrm{MPa}$. Similarly for the total Von Misses strain that reached the maximum at $0.00105 \mathrm{~mm} / \mathrm{mm}$ (at rake angle of $-15 \mathrm{deg}$ ). This was agreeable with Lo [11] who found that the normal and effective stress acting on the edge of carbide cutting tool decreases with increases in rake angle from negative to positive value. According to him, the stress on the edge of carbide cutting tool decreases when rake angle increases.

Figure 12 shows that the temperature on the cutting edge of carbide tool had increased from $1170^{\circ} \mathrm{C}$ to $2200^{\circ} \mathrm{C}$ when the rake angles were increased from 0 to $+15 \mathrm{deg}$. The temperature were decreased from $1170^{\circ} \mathrm{C}$ to $981^{\circ} \mathrm{C}$ when the rake angles were increased from 0 to $-15 \mathrm{deg}$. This is aggreable with theory about friction and contacted wear that will be explained later. In this simulation, the carbide tool was designed with constant geometrical model, whereas, the rake and clearance angles were varied accordingly.

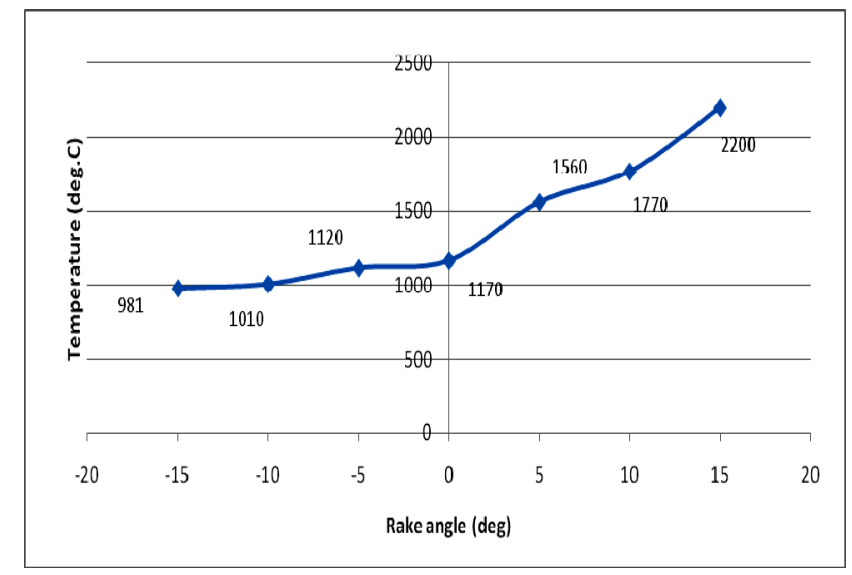

Figure 12 The generated temperature on cutting edge at positive rake angle $(+15$, +10 , and $+5 \mathrm{deg}), 0 \mathrm{deg}$, and at negative rake angle $(-5,-10$, and $-15 \mathrm{deg})$.

Change of the rake angle had caused the clearance angle to be changed accordingly, i.e. when the rake angle was increased to certain degrees, the clearance angle was also decreased with the same degree. For example, when the rake angle was increased from +5 to $+10 \mathrm{deg}$, the clearance angle will accordingly also decreased from 15 to 10 deg as illustrated in Figure 13. In other word, as the rake angle was increased in certain degrees, the clearance 
angle decreased in the same degrees. Smaller clearance angle caused more the area contact and friction between the clearance face and work piece, then caused more temperature on the cutting tool during cutting process with increasing rake angle (decreasing clearance angle).

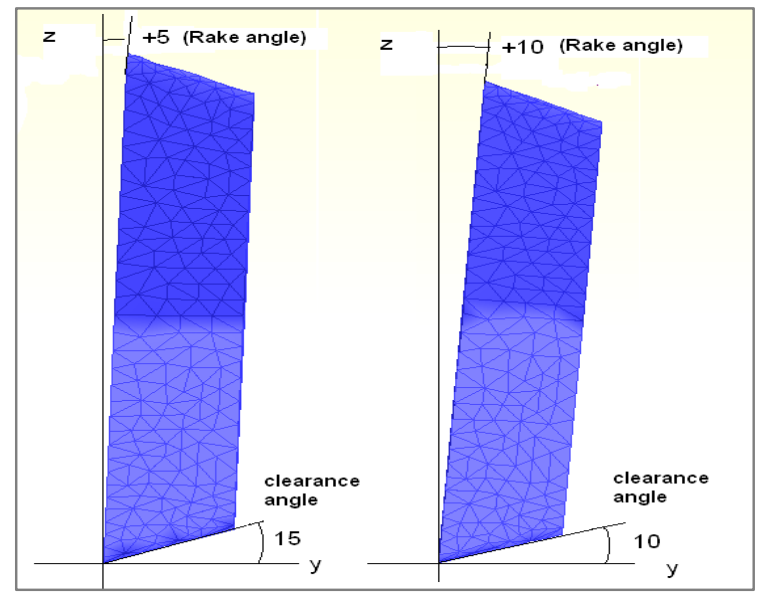

Figure 13 Change of the rake angle in $5 \mathrm{deg}$, cause the clearance changed conversely in $5 \mathrm{deg}$ (The clearance angle changed, but shape is remained constant).

The larger the contact area between the clearance face and work piece, the more friction occur during machining, consequently more wear occurred that contribute to more temperature generated on the edge of carbide cutting tool. This was also aggreable with the theory that the smaller the clearance angle, the bigger the contact area between the clearance face and the work piece as found by Stephenson, et al. [12] and Yanda, et al. [13]. Coelho, et al. [14] found that small changes in clearance angle will greatly influence the wear mechanism and consequently the tool life.

Besides, this also agreable with Cerenitti [15] who conducted the machining simulation for AISI 1045 in various rake angles from -5 to $50 \mathrm{deg}$. They said that the maximum temperature of the tool cutting increased with increasing tool rake angle while the chip temperature decreased with increasing tool rake angle.

\subsection{Stress, Strain and Generated Temperature on Workpiece}

The biggest deformation was occurred in the primary deformation zone, followed by the secondary deformation zone as shown in Figure 14. This also caused the higher effective stress occurred in this section, which reached 1920 $\mathrm{MPa}$ (contour line I). This result is agreeable with Kalhori [16] where the major 
deformation during cutting process were concentrated in two region close to the cutting edge, and the bigger deformation were occurred in the primary deformation zone, followed by the secondary deformation zone.

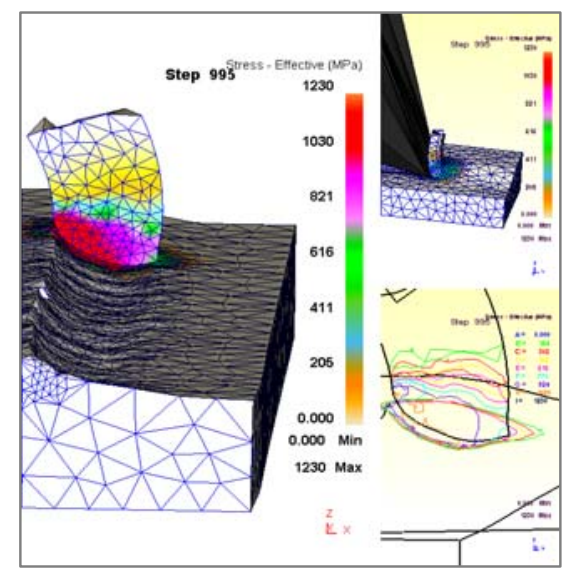

Figure 14 Effective stress in work for the rake angle of $+15 \mathrm{deg}$, cutting speed of $100 \mathrm{~m} / \mathrm{min}$, feed rate of $0.35 \mathrm{~mm} / \mathrm{rev}$ and depth of cut of $0.3 \mathrm{~mm}$.

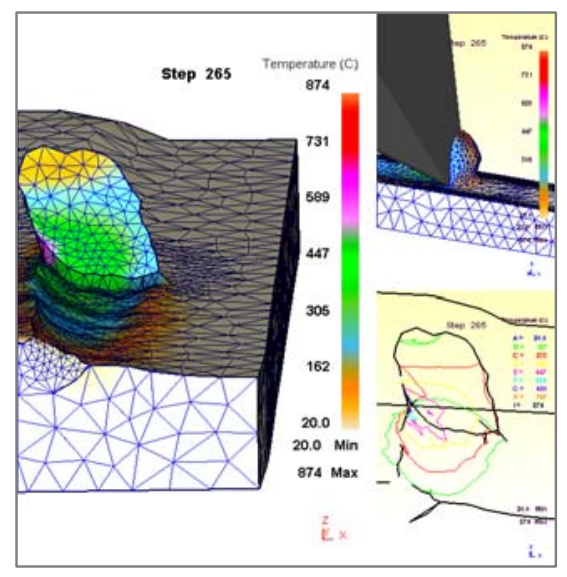

Figure 15 Generated temperature on chip formation for the rake angle of $+15 \mathrm{deg}$, cutting speed of $100 \mathrm{~m} / \mathrm{min}$, feed rate of $0.35 \mathrm{~mm} / \mathrm{rev}$ and depth of cut $0.3 \mathrm{~mm}$.

The temperature on workpiece can be analyzed in detail based on the contour in Figure 14. A higher temperature of $874^{\circ} \mathrm{C}$ in contour lines I is obtained, followed by $\mathrm{H}\left(767^{\circ} \mathrm{C}\right), \mathrm{G}\left(660^{\circ} \mathrm{C}\right)$ and etc. Figure 15 shows the contour of effective stress on workpiece and chip formation. The highest temperature on the chip usually occurred in this sliding region, while the heat generated in the sticking region caused the workpiece material to adhere with the tool. Later it was sheared which resulted in high frictional force, consequently high temperature was generated. These results are also agreeable with finding of Kalhori [16]. According to El-Hofy [17], theoretically, most of heat or generated temperature is carried away by the chip. The theory also tells that during the machining, it is assumed that all the cutting energy is converted to heat and, therefore, a considerable amount of heat is generated at the following three distinct zones, these are 1). Shear zone (75\%); 2). Chip sliding on the tool face $(20 \%)$; c). Tool sliding on the workpiece machined surface $(5 \%)$ which neglected for perfectly sharp cutting tools. The maximum heat is produced at the shear zone because of the plastic deformation of the metal, practically all of this heat is carried away by the chip. 


\section{Conclusion}

Based on the simulation results, it can be concluded that:

a. Increasing the rake angle in positive section caused the decrease of the cutting force. On the other hand, increasing the rake angle in negative section, increases the cutting force.

b. Increasing the rake angle in positive section decreasing the effective stress, and the total Von Misses strain, especially at the rake angle of $+15 \mathrm{deg}$ those values are minimum. On the other hand, increasing the rake angle in negative section increases the effective stress and total Von Misses strain. The minimum total Von Misses strain was obtained at the rake angle of +15 deg. Therefore, the optimum cutting force, effective stress and total Von Misses strain for this simulation is obtained at rake angle of $+15 \mathrm{deg}$.

c. Increase of the rake angle caused to be reduced accordingly the clearance angle. Smaller clearance angles caused more the contact area and friction between the clearance face and the work piece, this also increased the temperature on cutting edge. The optimum temperature was obtained at rake angle of -5 deg.

d. The biggest deformation (chip formation) was occurred in the primary deformation zone, followed by the secondary deformation zone. Therefore the highest stress was also occurred in this area. The highest temperature on the chip usually occurred in the sliding region, while the heat generated in the sticking region caused the workpiece material to adhere with the tool. Later, it was sheared which resulted the high frictional force and generated higher temperature in the sliding region.

e. All of the results are agreeable with theory and some simulations and experiments in references.

\section{Acknowledgment}

The authors would like to thanks for the Government of Malaysia and Universiti Kebangsaan Malaysia for their financial support under 03-01-01SF1214 and UKM-GUP-BTT-07-25-025 Grants.

\section{References}

[1] Marusich, T.D., Ortiz, Modeling and Simulation of High-Speed Machining, International Journal for Numerical Methods in Engineering 38(21), 3675-3694, 1995.

[2] Cerenitti, A.E., Fallbohmer, B.P., Wu, C.W.T. \& Altan, B.T., Application of $2 D$ FEM to Chip Formation in Orthogonal Cutting, Journal of materials Processing Technology, 59, 169-180, 1996. 
[3] Cerenitti. A.E., Lazzaroni, C., Menegardo, L. \& Altan, T., Turning Simulation Using a Three-Dimensional FEM Code, Journal of materials Processing Technology, 98, 99-103, 2000.

[4] Xie, J.Q., Bayoumi, A.E. \& Zbib, H.M., FEA Modelling and Simulation of Shear Localized Chip Formation in Metal Cutting, Journal of Materials Processing Technology, 38, 1067-1087, 1998.

[5] Shet, C., Finite Element Analysis of the Orthogonal Metal Cutting Process, J. of Materials Processing Technology, 105, 95-109, 2000.

[6] Jawahir, I.S., An Intermediatary Level Short Course on Machining Process Modelling and Optimization for Improved Productivity, Machining Research Laboratory Center for Manufacturing, Department of Mechanical Engineering Lexington, USA, 2008.

[7] Columbus, O.H., Deform ${ }^{T M}$ - 3D Machining (Turning) Lab, Scientific Forming Technologies Corporation, 2007.

[8] Mackerle, J., Finite Element Analysis and Simulation of Machining: a Bibliography (1976 - 1996), Journal of Materials Processing Technology, 86, 17-44, 1999.

[9] Oxley, P.L.B., Mechanics of Machining: An Analytical Approach to Assessing Machinability, Ellis Horwood, Chichester, West Sussex, pp. 223-227, 1989.

[10] Gunay, M., Korkut, I. \& Seker, U., Experimental Investigation of The Effect of Cutting Tool Rake Angle on Main Cutting Force, Journal of Material Processing Technology, 166, 44-49, 2005.

[11] Lo, S.P. An Analysis of Cutting Under Different Rake Angles Using the Finite Element Method, Journal of Materials Processing Technology, 105, 143-151, 2000.

[12] Stephenson, A.A., \& Agapiou, J.S., Metal Cutting Theory and Practice, Marcel Dekker. Inc, New York, 1996.

[13] Yanda, H., Ghani, J.A., \& Che Harun, C.H., Machining and Cutting Simulation: Effect of Rake Angle and Clearance Angle on Wear Cutting Insert Carbide, Proceeding National Tribology Conference, Rimba Ilmu, University of Malaya, 4-5 May 2009.

[14] Coelho, R.T., Silva, L.R., Braghini, A. \& Bezerra, Jr. A. A., Some Effect of Cutting Edge Preparation and Geometric Modifications When Turning Inconel 718TM at High Cutting Speed, Journal of Materials Processing Technology, 148, 147-153, 2004.

[15] Cerenitti, E., Fallbohmer, P. \& Altan, T., Application of 2D FEM to Chip Formation in Orthogonal Cutting, Journal of Materials Processing Technology, 59, 169-180, 1996.

[16] Kalhori, V, Modelling and Simulation of Mechanical Cutting, Doctoral Thesis, Institutionen for Maskinteknik, Sweden, 2001.

[17] El-Hofy, H., Fundamentals of Machining Processes: Conventional and Nonconventional Processes, Published by CRC Press, 2006. 
http://books.google.com.my/books?id=ZdQEZ5pyCv4C\&vq=cutting + spe ed\&dq=affecting, + temperature,,+ cutting + speed\&source $=$ gbs_summary_s $\& \mathrm{cad}=0$, (November, $\left.10^{\text {th }} 2008\right)$. 